\title{
Research on the Integration of Modern Information Technique and Athletics Teaching
}

\author{
Dachuan WANG \\ Sichuan University, China
}

\begin{abstract}
With the rapid development of information technology and acceleration of global economic integration, profound historical reforms are taking place in many aspects of social life and economic sector in our country since we enter the new era. In the keen international competition, informatization education and its application in a country and a region will directly affect the comprehensive competitiveness of the whole country and nationality and thus become the important mark measuring its development level. In the current society, information technology and education are inseparable and undoubtedly, information technology exerts an influence on supporting and improving teaching and learning. In view of the necessary trend, Chinese Ministry of Education has determined the integration of accelerating information technology with other subject courses as one of the important goals of education for elementary and middle schools. Thus the integration of information technology with other course teaching has become a hot spot subject of the information technology education and even the whole education informatization progression in our country. Currently, the integration of modern information technique and athletics course exist a certain margin in the development theory and practice in our country. The author studies these problems and puts forward some viable suggestions in this thesis.
\end{abstract}

KEYWORD: Information technique; The athletics course; Integration

\section{THE NECESSARY ANALYSIS ABOUT THE INTEGRATION OF MODERN INFORMATION TECHNIQUE AND ATHLETICS TEACHING}

\subsection{Athletics Teaching Reform and Development Needs}

From the view of education, the characteristics of the modern information education technology are multimedia materials, resource globalization, teaching individualization, learning selfindependence, cooperatives task, management automation and so on. Under the condition of modern information technology, students can select learning and training content according to their own physical conditions and their interest in sports. It can give full play to the potential of students, but also meet students' personalized requirements. Thereby, the purpose on the education of students according to their aptitude can achieve. From teachers' perspective, the athletics teachers must study hard, master the modern teaching means and enrich themselves constantly. Only in this way can they stand the forefront of the information age development and meet the challenge of network information. In the end, they will become the main force of physical education modernization development. Therefore, strengthening the organic integration of modern information technology and the school athletics teaching is athletics teaching reform and development needs.

\subsection{It makes for a variety of Sports Teaching Modes.}

In the traditional sports teaching, the teachers only make the students know about requirements and finish the exercise according to the teacher's explanation demonstration. We must break the traditional sports teaching mode and construct an open, development-oriented modern sports teaching view. We must take advantage of computer, multimedia technology as the core of the modern education technology, implement in image, video, animation, sound, and other media to intuitive realistically reflect the dynamic changes of the sports technique process and build all kinds of high quality sports teaching mode. By computers, multimedia, network the school sports teaching has brought the resource of sports teaching across time and space limit. 


\subsection{Optimize the Structure of Classroom Teaching and Improve the Teaching Effect.}

Because of the integration of modern information technique and athletics teaching, teachers can set students practice activities scientifically, make the students active to the hilt and participate in practice actively. Students can choose their favorite sports and get various expert guidance by the immediate feedback of the network. Students can obtain information related to sports through the network, make full use of the valuable sports information resources and get sports teachers' appropriate guidance and inspiration. With modern multimedia technology as well as a variety of excellent sports teaching software, we can use the teaching frame switching, superposition of sound effects, animation effects processing. By this way, some hard actions that teachers can not demonstrate clearly can demonstrate to the students by slow motion, replay, stop lens combination interpretation methods. So it can help students see each technical detail, establish action representation faster, more comprehensive, more accurate, deepen the understanding of action, and then seize the key part of action, improve the efficiency of cognitive stage motor learning, shorten the teaching process and improve the teaching effect.

\section{HINDERED THE ADVANCE OF MODERN INFORMATION TECHNOLOGY AND PHYSICAL EDUCATION TEACHING PROCESS}

\subsection{Hardware}

If you infuse the modern information technology into the teaching of sports, there must be some information technology resources to provide a solid content for physical education curriculum integration. If there is not enough enrichment and social demands of the teaching content and resources to meet the needs of the reform of physical education. And if it cannot meet the needs of today's modern social informatization development network resources, it will lead to information technology in physical education teaching reform will not be able to get a good popularization and application. Although the colleges and universities are popular in network resources. But it didn't used well in physical education teaching reform. At the same time, the current teaching resources are improved no matter from content and form. But it is still difficult to adapt to the pace of the new curriculum reform. It will not be able to meet the needs of the physical education teaching reform.

\subsection{Software}

Because of the intervention of modern information technology, put forward the general college sports teachers to a higher request, only a few people can apply these devices yet. At present some colleges and universities are equipped with modern teaching facilities, including computer, database, network, communication and microelectronics, image processing, simulation and other technical equipment, but most of the faculty is also difficult to master these high-tech teaching tool in a short period of time. And even some people are not good at it, someone are resist to this even. Secondly, the teacher's innovation ability needs to be improved. Under the background of physical education teaching reform, put student's sports innovation to a high desire. Only the innovative ability of physical education teachers can improve the indicators. In the new period, the teacher should not only possess the ability of teaching, more important is that the teachers should grasp the knowledge of mastering new tools, new methods and new ways according to the needs of times development.

\subsection{The Degree of Sports Value is not High}

Since the country launched the reform of education system, students pay a close attention to this, but this did not get enough attention from the public. The state has been advocated a moral, intellectual, physical all-round development for a long time. But colleges and universities are naturally focused on the moral education and intellectual education in the process of implementation.

\subsection{Lead to a lot of students will have sports as a course which is not unnecessary}

It also affects the physical education curriculum teaching of many teachers. In the long-term negative social consciousness guidance, it is very difficult for teachers and students to accept such a kind of new education idea and education mode quickly in a short period of time. There is no doubt that the ideology also need a process to reverse.

\subsection{The Application of Modern Information Technology in the Sports Teaching is lack of Systematic and Scientific}

The application of modern information technology are not connected in most cases. It cannot form a continuum. There are only a few people in many schools use of some resources, such as network resources, but only a few teachers can master and use the high technical resources. For example only few people can master the analysis instrument and the image processing software which can improve the athletes technology moves. Also the teaching in the field of e-sports is not very common. The professional teachers are relatively less. When the teachers use the modern information technology to 
teach do not cultivate students' sports ability at the same time, most of the time they use the information technology as a temporary project, rather than use the information systems technology record, analyze and improve student's physical quality or sports skills.

\section{THE VIABLE SUGGESTIONS ABOUT THE INTEGRATION OF MODERN INFORMATION TECHNIQUE AND ATHLETICS TEACHING}

\subsection{Construct Sports Information Resources Platform.}

In order to promote the knowledge update, we should construct sports information resources platform. With the aid of network information resources to promote the spread of sports fitness consciousness. The construction of our country sports resources sharing platform is the carrier that carry out athletics teaching reform and the inevitable way to realize the goal of physical education teaching reform. The share of domestic and international sports information. At present, the application in the field of sports like some important discoveries and development of related disciplines and high-tech achievements make some traditional sports scientific research methods and technology updated and breake some traditional concepts and theories. If we cannot seize sports science area rich and valuable information promptly and update old knowledge then teach students, we will not realize the improvement of quality of educators themselves and develop cross-century talents in sports. At home and abroad, the different characteristics and categories of web sites can provide us with a lot of valuable information, search the information through the network can greatly reduce our costs and let us grasp the dynamics of international sports quickly and change their own skills rapidly. As a sports worker, he should set up the consciousness of modern sports information, have the skill of acquisition network information and learn to share the global sports information resources. Take advantage of network resources to carry out distance education. With the development of computer network technology, the popularity of computer in colleges and universities and society's need for continuing education of higher learning, network distance education will become the trend and direction of the college education reform. College physical education should make full use of its advantages, use the modern education technology and network technology to promote teaching reform and meet the requirements of social development. Through distance network education realize continue education, colleges and universities sports teaching should make full use of their own advantages. Through the online teaching courseware and online teaching resources to push network remote sports education developed. At the same time, in order to stop the lack of online sports teaching resources, we should create online sports teaching resources combined with professional knowledge and modern education technology.

\subsection{Strengthen the Teacher and the Students' Sports Consciousness}

A lot of people still remember the SARS in 2003, we can see from the "SARS" outbreak, people do not take the case seriously due to does not agree with the necessity of this things. Since the "SARS" set up the awareness for the people to exercise, many social units, organizations and individuals will take morning exercise or eat breakfast every day. To enhance people's physical quality, everyone should have the consciousness of taking exercise. So the sports teaching for students in order to receive the good results, students need to solve the question of consciousness firstly. So the school leadership should give physical education teaching in a very important position. At the same time, school leadership should take advantage of advanced network resources to provide convenient and practical services for students. Strengthen students' sports consciousness repeatedly.

\subsection{Sports Teaching Systematic and Scientific}

Under the influence of traditional thinking for a long time, many teachers will regard physical education curriculum teaching as a task to implement and do not think this kind of systematic teaching process and the results. We can help student's scientific growth and development by using the modern information technology and train the advantages and disadvantages of students. Professional profile can be established to measure for athletic performance.

\subsection{Improve the Teachers' Physical Quality}

Teachers' level of mastery of modern information technology is a very important problem in the sports teaching. So it is imperative to improve teachers' information technology literacy. This is inevitable in the process of information technology application in physical education. First of all, we should improve teachers' information quality. As a sports teacher, sports information should be able to screen out and they should have the sensitivity of information. They should know some information that come from domestic and international sports project, and adjust their teaching content, form and means. Secondly, promote teachers to grasp the technology and equipment. Modern information technology can become an important teaching method depends on the degree of physical education teachers grasp the 
modern information technology. So we must strengthen the physical education teacher's technology of modern information, the teacher not only to master the software but also need to have a good understanding and mastering of the hardware facilities.

\section{CONCLUSION}

Mankind has entered the information age, modern information technology has entered the school gate. Only know the relationship between the teaching of modern information technology and traditional sports teaching clearly, modern information technology teaching can have a very important role in the sports teaching. Getting multimedia information technology and modern education technology together is a new type of teaching method in physical education teaching reform. As sports worker should use modern information technology to assist teaching in the sports teaching. This can improve the students' interest in learning and teaching effect greatly.

\section{REFERENCES}

[1] McKienan G. Multimedia Information and Technology. Embedded Multi mediain Electronic Journals. 1999

[2] W.J. Crowther, J. R. Potts. Simulation of a spin stabilised sports disc. Sports Engineering. 2007 (1)

[3] Baker, W.E. Three-dimensional block models. Journal of Mathematical Sociology. 1986

[4] R. J. Ong, J.T. Dawley and P.G. Chinese school sports (2003)

[5] P. G. Clem, M. Rodriguez, J. A. Voigt and C. S. Ashley, Practice of Physical Education Reform. (2001)

[6] Li ChunXiao, Based on PE Teaching Evaluation System to explore career outlook, in: B. S. Jones, R.Z. Smith (Eds.), Introduction to the Electronic Age, E-Publishing Inc., New York, 1999. 